\title{
VULNERABILIDADE NATURAL À PERDA DE SOLOS NA FLONA BOM FUTURO E SEU ENTORNO PRÓXIMO/ESTADO DE RONDÔNIA
}

\section{Natural vunerability to the soils's loss in the Flona - Bom Futuro and its surround/Rondônia State}

\author{
Alex Mota dos Santos \\ alex.geotecnologias@gmail.com \\ Professor Adjunto da Universidade Federal de Goiás \\ Emanuel Fernando Correia Sanches Schott \\ Graduado em Engenharia Ambiental pela Fundação Universidade Federal de Rondônia \\ Daniel de Oliveira Soares \\ Mestrando em Ciência e Sistemas de Informação Geográfica pela Universidade Nova de Lisboa, \\ UNL, Portugal. \\ RESUMO: A Floresta Nacional (FLONA) do Bom Futuro, localizada no município de Porto Velho, estado \\ de Rondônia, sofreu intensa ocupação a partir da década de 90 . Como efeito, é possível que a \\ ocupação na área da FLONA tenha afetado a estabilidade do solo, deixando-o susceptível à erosão. \\ Neste sentido, o objetivo do trabalho foi mensurar e quantificar a vulnerabilidade natural à perda de \\ solos na FLONA Bom Futuro e seu entorno a partir de métodos indiretos, nomeadamente, o \\ processamento digital de imagens de sensoriamento Remoto e álgebra de mapas a partir de um \\ Sistema de Informação Geográfica (SIG). Como resultado identificou-se que a retirada da vegetação \\ nativa pode interferir na estabilidade do solo, sendo o dano minimizado pela sua estrutura e da geologia \\ encontrada na área. Além disso, observou-se que foi a terra indígena a área especial que mais contribui \\ para conservação da floresta.
}

Palavras-chave: Susceptibilidade à erosão do solo, Impactos ambientais, Unidades de Conservação, Amazônia Ocidental.

ABSTRACT: The National Forest (FLONA) of the Bom Futuro, placed in Porto Velho county, Rondonia state, Brazil, suffered an occupation since 1990. Indeed, it is possible that occupation in FLONA area had been affected the soil stability, letting it susceptible to erosion. In this sense, the goals from that work had to measure and quantify the natural vunerability to the soils's loss in the FLORA - Bom Futuro and its surround from indirect methods, namely, the digital processing of remote sensing and algebra of maps from the Geographic Information Systems (GIS). How result indentified that the withdrawal of native vegetation may interfere in ground stability, being the damage minimized by soil structure and the geology found in the area. Besides that, it was observed that was indigenous land the special area that more contributed to forest conservation.

Key words: Susceptibility to soil erosion, Environmental Impacts, Conservation Units, Western Amazon. 
VULNERABILIDADE NATURAL À PERDA DE SOLOS NA FLONA BOM FUTURO E SEU ENTORNO PRÓXIMO/ESTADO DE RONDÔNIA

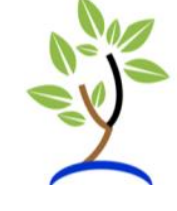

\section{INTRODUÇÃO}

As áreas especiais, unidades de conservação, sejam elas de proteção integral ou de uso sustentável e as terras indígenas são importantes para conservação da Floresta Amazônia. Nesse sentido, Veríssimo et al. (2011, p. 11) revelam que "a criação e a manutenção de Áreas Protegidas - Unidades de Conservação (UCs) e Terras Indígenas (Tls) - é uma das estratégias mais eficazes para a conservação dos recursos naturais na Amazônia". Ferreira et al. (2012) corroboram afirmando que o aumento do desmatamento fora das áreas protegidas mostra claramente a importância do atual mosaico de unidades de conservação e terras indígenas na região.

Por sua vez, a floresta conservada sustenta serviços ambientais diversos, serviços ecossistêmicos e/ou benefícios prestados pelas florestas, dos quais destacamos sua importância para a conservação da biodiversidade, a proteção dos solos do processo de erosão, manutenção das chuvas, regulação do clima local, regional e do planeta (LAURANCE, 2005; FERREIRA, 2005; ASNER, et al., 2010; CASTELLO, et al. 2013; SANTOS, 2014; REZENDE et al., 2017).

De modo que as análises que se propõe discutir os cenários de alterações do meio físico a partir da análise do uso e cobertura dessas áreas são recorrentes (FERREIRA, 2005; MMA, 2009; GOMES et al., 2011; SANTOS, 2014) e importantes, mas não atingem todas as unidades de conservação, nem tão pouco, as terras indígenas. A partir de tal constatação, esse artigo apresenta a análise da alteração do meio físico, a partir da mensuração e quantificação da vulnerabilidade natural à perda de solos na Floresta Nacional (FLONA) do Bom Futuro e seu entorno, no estado de Rondônia, parte da Amazônia Ocidental. Os trabalhos de pesquisa estão associados ao grupo de estudo em Geografia Socioambiental, que vem desenvolvendo, dentre outras análises, aquelas voltadas para avaliação do desmatamento em áreas do entorno das terras indígenas e unidades de conservação desde o ano de 2011 e os resultados já foram apresentados em diversos trabalhos, dos quais destaca-se Santos (2014), Santos e Gomide (2015), Santos e Mendonça (2016), Santos e Mota (2017).

A importância da análise sobre essa área advém do fato de que, a partir de dados do Ministério do Meio Ambiente (MMA, 2009), até o final da década passada, $25 \%$ da FLONA Bom Futuro havia sido ilegalmente explorada e transformada em pastagem e um total de 35 mil cabeças de gado e 3 mil pessoas estavam presentes dentro dos limites da mesma. Além disso, segundo dados do Instituto do Homem e do Meio Ambiente da Amazônia (IMAZON) (FONSECA et al., 2016), o estado de Rondônia tem 3 das 10 Unidades de Conservação mais desmatadas da Amazônia. A Reserva Extrativista (RESEX) Jaci-Paraná e Área de Proteção Ambiental (APA) do Rio Pardo, incluídas na área de estudo faz parte da relação apresentada pelo IMAZON. Portanto, estudar a FLONA do Bom Futuro e seu entorno é reforçar os estudos já realizados.

Desse modo, acredita-se que a criação de gado bovino seja uma das principais atividades econômicas que motivam o desmatamento nessas áreas, pois a área de pastagem e o número de bovinos crescem ano após ano. Neste sentido, sabe-se que a vegetação cumpre um importante papel na conservação do solo, protegendo-o dos processos erosivos causados principalmente pela chuva e pelo escoamento 
superficial e a perda da vegetação afeta diretamente esse recurso natural. Com efeito, segundo Faria et al. (2003) a erosão é um processo natural de degradação, decomposição, transporte e deposição de materiais de rochas e solos e é a principal forma de degradação dos solos (WINCANDER e MONROE, 2009).

Dessa maneira, Smith e Wischmeier (1962 apud GUTH, 2010) mencionam que quatro fatores e suas interações são determinantes no processo erosivo hídrico: o clima, representado principalmente pela ação da precipitação pluviométrica; o solo, considerando sua resistência a degradação; a topografia, notadamente a declividade do talude e; o tipo de cobertura do solo. Para Santana et al. (2007) a suscetibilidade que os solos têm em ser erodidos é influenciada também pelas suas características físicas, principalmente aquelas que afetam sua capacidade de infiltração e permeabilidade, e sua capacidade de resistir ao desprendimento e transporte pela chuva e enxurrada.

Portanto, como consequência das atividades humanas, o aceleramento dos processos erosivos resulta na perda de solos férteis, a poluição da água, o assoreamento dos recursos hídricos, a degradação e a redução da produtividade global dos ecossistemas terrestres e aquáticos. Além disso, Abdon (2004) afirma que a erosão causa a degradação do solo prejudicando a fertilidade, alterando a profundidade do solo, o qual é responsável por grande parte da matéria orgânica presente no solo, pelos nutrientes necessários ao crescimento e manutenção das plantas e pela melhor estrutura para o desenvolvimento das raízes. Além da perda de nutrientes, a erosão do solo causa grande aporte de sedimentos para os cursos d'água e, como citado por Carvalho et al. (2006), tais refluxos podem causar impactos eutróficos, ou de outro tipo rio abaixo, afetando toda a biota presente neste ecossistema. Portanto, reforça-se que realizar análises que revelem cenários de comprometimento dos recursos naturais em áreas especiais, terras indígenas e unidades de conservação, é imperativo na Amazônia.

Assim, tem-se observado que as análises do meio físico são realizadas de forma direta e indireta. De forma direta predomina experimentos em áreas restritas, in loco, e de forma indireta utiliza-se de ferramentas de análises espaciais a partir de dados previamente tratados e muitas vezes de fontes diversas. Nesse sentido, na análise do meio físico tem sido recorrente a utilização de ferramentas de geotecnologias, que é o foco dessa análise, portanto vista com maior detalhe nos próximos tópicos.

\section{MATERIAIS E MÉTODOS}

\section{Área de Estudo}

O estudo de caso foi realizado na área da Floresta Nacional Bom Futuro. Também foi considerada uma área de influência ou buffer de $10 \mathrm{~km}$ além dos limites da mesma (Figura 1). 


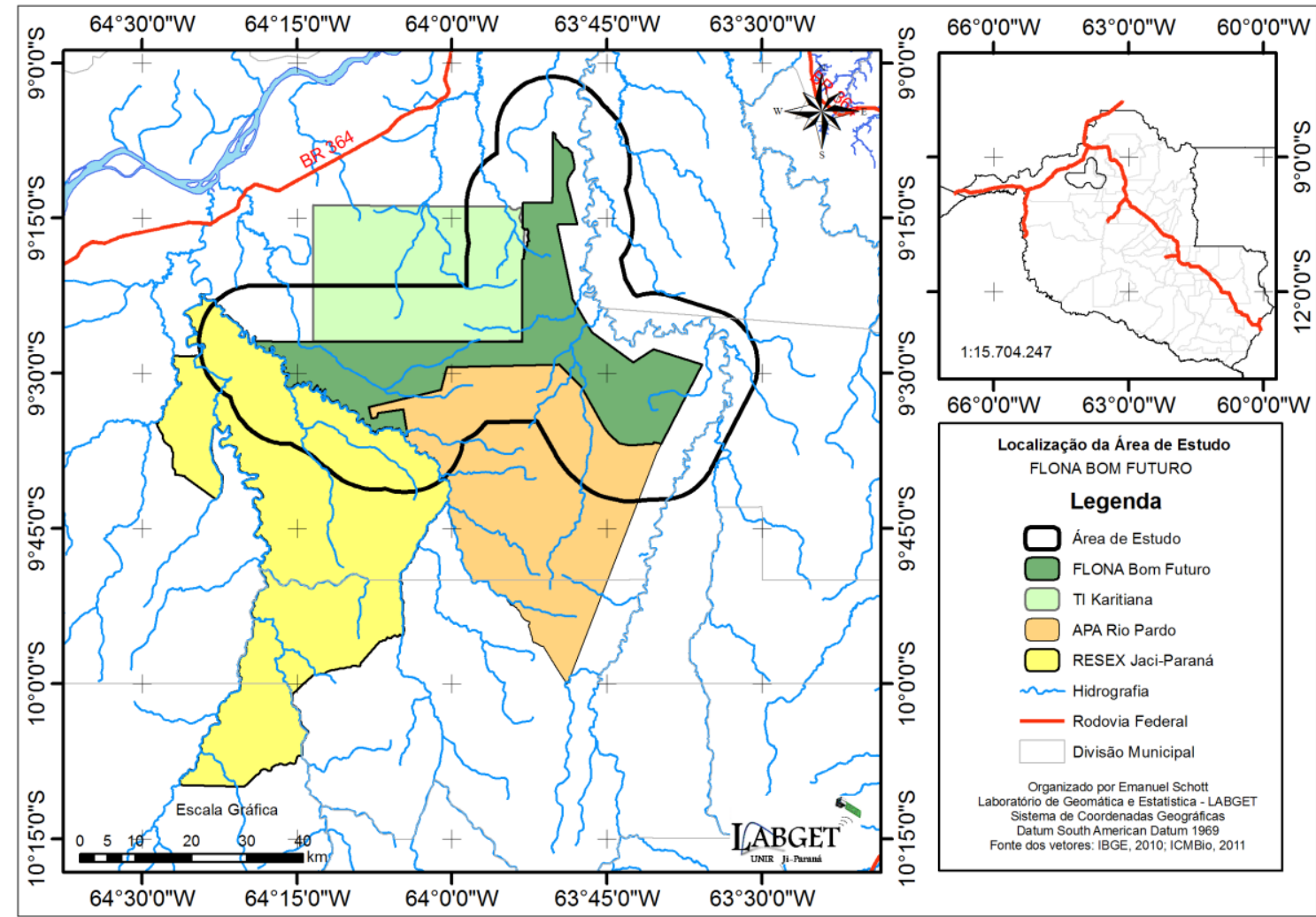

Figura 1 - Localização da Área de Estudo.

A definição da área de influência seguiu a legislação anterior a 2015, que definia que a área deveria ser de $10 \mathrm{~km}$ ou aquela definida no plano de manejo das unidades e conservação. A partir de 2015 a legislação brasileira reduziu para $3 \mathrm{~km}$ a área de influência, considerada aqui com restrita para os cenários de conflitos na Amazônia.

A FLONA Bom Futuro possui 97.357 hectares e ocupa área dos municípios de Porto Velho, Alto Paraíso e Candeias do Jamari. A área total de estudo, incluindo a área de influência é de aproximadamente 387 mil ha. Além disso, é importante referir que a FLONA Bom Futuro faz fronteira com outras Unidades de Conservação, sendo elas a Reserva Extrativista (RESEX) Estadual Jaci-Paraná e a Área de Proteção Ambiental (APA) Estadual do Rio Pardo, esta última remanescente do desmembramento da própria FLONA Bom Futuro. Além disso, está contida na área de influência parte da área da terra indígena Karitiana.

\section{Procedimentos Metodológicos}

A metodologia seguiu a proposta de Crepani et al. (2001) para cálculo da vulnerabilidade natural à perda de solo na Amazônia. De forma geral, esta metodologia se baseia na pedogênese (processo de formação do solo) e morfogênese (processo de modificação do solo). Segundo o autor sua caracterização é feita a partir 
dos critérios baseados nos conceitos de Ecodinâmica de Tricart (1977 apud Crepani et al., 2001).

Nesse sentido, a metodologia proposta por Crepani et al. (2001) e aplicada em diversas pesquisas (CAVALCANTE et al., 2010; ROVANI et al., 2017), inclusive no estado de Rondônia (GOMES et al., 2011; MENDES, 2012) ofereceu recursos valiosos para análise das alterações do meio físico e estabelecimento de cenários ambientais em áreas de desmatamento.

Na metodologia proposta por Crepani et al. (2001) são definidas Unidades Territoriais Básicas (UTB) como uma entidade geográfica que contém atributos ambientais (geologia, pedologia, geomorfologia, vegetação, clima) que permitem diferenciá-la de suas vizinhas, ao mesmo tempo em que possui vínculos dinâmicos que a articulam à uma complexa rede integrada por outras unidades territoriais.

Dessa forma, às UTB são associados pesos de vulnerabilidade que são descritos integralmente em Crepani et al. (2011) e classificados da forma como aparece na Tabela 1.

Tabela 1 - Valores atribuídos as unidades estáveis, intermediárias e instáveis.

\begin{tabular}{ccc}
\hline UNIDADE & RELAÇÃO PEDOGÉNESE/MORFOGÉNESE & VALOR \\
\hline Estável & Prevalece a pedogênese & 1 \\
Intermediária & Equilíbrio entre pedogênese e morfogênese & 2 \\
Instável & Prevalece a Morfogênese & 3 \\
\hline
\end{tabular}

Fonte: adaptado de Crepani et al. (2001).

A avaliação da vulnerabilidade natural à perda de solos para cada tema dentro das UTB é realizada a partir de uma média aritmética entre os valores definidos para cada tema, conforme pode ser visto na Equação 1. Vale destacar que para o tema geomorfologia, são considerados três fatores: a amplitude interfluvial, a amplitude altimétrica e a declividade percentual, sendo assim, antes da inserção deste tema na Equação 1, é necessário obter uma média aritmética desses três fatores conforme descrito na Equação 2. O fluxograma do processo é apresentado na Figura 2 e todos os procedimentos de conversão e cálculo foram realizados no software Sistema de Processamento de Informações Georreferenciadas (SPRING), versão 5.2 .5 (CÂMARA et al., 1996).

$$
V=\frac{G+G e+S+V e+C}{5}
$$

Equação 1

Onde:

$\mathrm{V}=$ Índice de vulnerabilidade natural a perda de solo;

$\mathrm{G}=$ Vulnerabilidade para o tema Geologia;

$\mathrm{Ge}=$ Vulnerabilidade para o tema Geomorfologia;

$\mathrm{S}=$ Vulnerabilidade para o tema Pedologia;

Ve = Vulnerabilidade para o tema Cobertura do Solo;

$\mathrm{C}=$ Vulnerabilidade para o tema Clima.

$G e=\frac{A a+A i f+D p}{3}$

Equação 2 
VULNERABILIDADE NATURAL À PERDA DE SOLOS NA FLONA BOM FUTURO E SEU ENTORNO PRÓXIMO/ESTADO DE RONDÔNIA

\section{2}

Onde:

$\mathrm{Ge}=$ Vulnerabilidade para o tema Geomorfologia;

$\mathrm{Aa}=$ Vulnerabilidade para o tema Amplitude Altimétrica;

Aif $=$ Vulnerabilidade para o tema Amplitude Interfluvial;

$\mathrm{Dp}=$ Vulnerabilidade para o tema Declividade Percentual .

No total, 21 valores são possíveis de obtenção para a caracterização de cada UTB dentro de uma escala de estabilidade/vulnerabilidade. O valor 1, representa estabilidade, a estabilidade intermediária, 2, e 3, valor de maior vulnerabilidade.

Os dados de pedologia, geologia, geomorfologia e clima foram obtidos de fontes externas (Tabela 2). Assim, os dados geológicos foram obtidos junto ao Instituto Brasileiro de Geografia e Estatística (IBGE, 2012), escala de 1:1.250.000. Para a área de estudo, foi utilizada a carta "SC.20 - Porto Velho".

Tabela 2. Escala e fonte dos dados analisados.

\begin{tabular}{lcl}
\multicolumn{1}{c}{ Tema } & Escala & Fonte \\
Geologia & $1 / 1.000 .000$ & IBGE \\
Pedologia & $1 / 250.000$ & IBGE \\
Clima & $1 / 500.000$ & CPRM
\end{tabular}

Os dados de solos foram obtidos junto ao Instituto Brasileiro de Geografia e Estatística (IBGE, 2012) em formato shapefile (SHP) e escala 1:250.000.

Os dados geomorfológicos foram obtidos a partir da manipulação das cenas do Shuttle Radar Topography Mission (SRTM), carta SC-20-V-D, obtidos junto ao sítio da Empresa Brasileira de Pesquisas Agropecuárias (EMBRAPA).

Os dados de uso e cobertura do solo, especialmente para análise da vegetação, foram obtidos a partir do processamento digital de imagens. Nesse sentido, utilizou-se imagens do sensor Operational Land Imager (OLI) do Land Remote Sensing Satellite 8 (LANDSAT 8) que foram obtidas gratuitamente junto ao sitio do Serviço Geológico dos Estados Unidos (USGS, 2013). Assim, utilizou-se as bandas 4, 5 e 6, correspondentes as faixas do Vermelho, Infravermelho Próximo e SWIR 1 respectivamente e que dão a composição dita falsa cor (SANTOS, 2014). A partir de testes em laboratório observou-se que essa composição foi a mais adequada para o caso em tela. Estas bandas permitem realizar uma composição colorida, de modo que os diferentes tipos de vegetação sejam facilmente identificados. A área de estudo foi coberta pelas órbitas/pontos 232/66, 232/67 e 233/66.

Às imagens aplicou-se a segmentação e posterior classificação. O processamento consiste na segmentação, no qual se divide a imagem em regiões que devem corresponder às áreas de interesse da aplicação. Entende-se por regiões um conjunto de "pixels" contíguos, que se espalham bidirecionalmente e que apresentam uniformidade (INPE, 2012). Para classificação da imagem segmentada utilizou-se o classificador Isoseg. Segundo o INPE (2012), este se trata de um algoritmo de 
agrupamento de dados não-supervisionado, aplicado sobre o conjunto de regiões, que por sua vez são caracterizadas por seus atributos estatísticos de média e matriz de covariância, e também pela área.

A legenda de uso e cobertura da terra foi definida em função da análise de MMA (2002), em que foram identificados três diferentes tipos de vegetação/cobertura: Floresta Ombrófila Aberta, Vegetação Secundária e Pastagem. Também foi detectado a presença de Queimadas.

Para análise da variável clima foram empregados os dados pluviométricos com escala de 1:5.000.000 junto ao CPRM (2006). Porém, para obtenção da intensidade pluviométrica, também se fazem necessários dados da média do período chuvoso. Assim utilizou-se dados de Crepani et al. (2001) do mapa da média do período chuvoso no Brasil desenvolvido pelo Instituto Brasileiro de Geografia e Estatística (IBGE).

Refere-se que as escalas não foram compatíveis, contudo, foram os dados possíveis identificados para o estado de Rondônia.

A associação do mapa de UTB aos dados temáticos ocorreu a partir das ferramentas de álgebra de mapas disponíveis no Sistema de Informação Geográfica utilizado. Os elementos da álgebra de mapas descrita por Tomlin consistem em mapas que associam a cada local de uma dada área de estudo um valor quantitativo (escalar, ordinal, cardinal ou intervalar) ou qualitativo (nominal) (CORDEIRO et al., 2007).

\section{RESULTADO E DISCUSSÕES}

Para Crepani et al. (2001) é recomendável a análise individual da vulnerabilidade por temas/variáveis ou UTB. Desse modo, na Figura 2 está espacializada a vulnerabilidade do tema geologia.

Para os autores supramencionados fatores como a história da evolução geológica do ambiente onde a unidade se encontra e o grau de coesão das rochas, ou seja, a intensidade da ligação entre os minerais ou partículas que as compõem, são levados em consideração na atribuição dos pesos. Desse modo, a partir da fonte dos dados de geologia constatou-se que o Complexo Jaci-Paraná é formado por material inconsolidados, portanto, de formação recente, instáveis e de fácil desagregação. Os sedimentos inconsolidados estão entre os mais instáveis à vulnerabilidade, especialmente quando ocorrem ao longo dos leitos dos rios, áreas onde uma grande quantidade de material é transportada pela água (GOMES, 2000). 


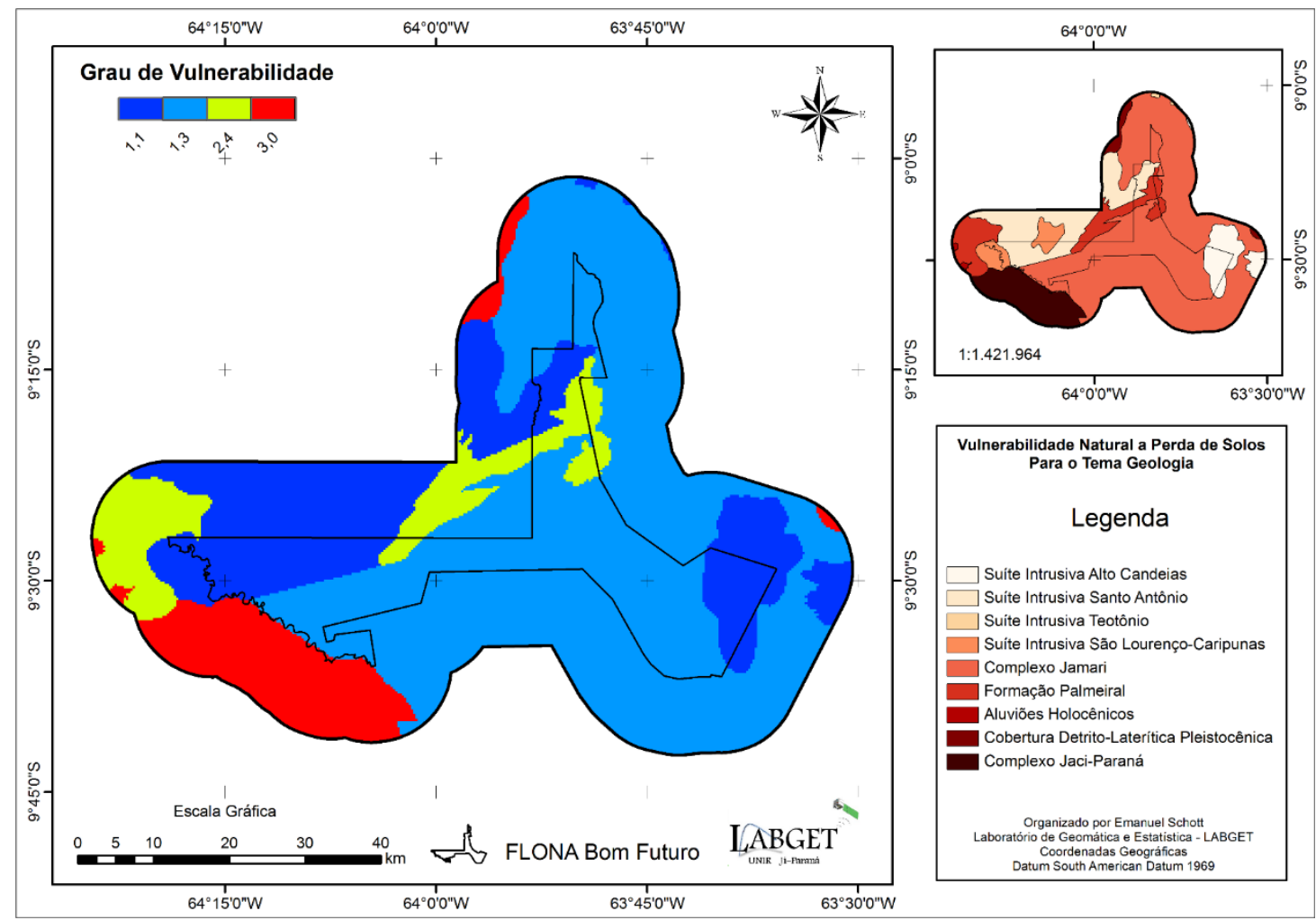

Figura 2. Vulnerabilidade natural à perda de solo para a variável de análise geologia.

Ao contrário, áreas sobre a Suíte Intrusiva Alto Candeias, apresentou baixa vulnerabilidade natural a perda de solos. Segundo Crepani et al. (2001), as formações Suítes Intrusivas são compostas basicamente por rochas graníticas, que se destacam por se apresentarem coesas. Os detalhes da análise para a variável geologia constam da Tabela 3.

Tabela 3. Unidades geológicas presentes na área de estudo.

\begin{tabular}{|c|c|c|c|c|c|}
\hline$\#$ & UNIDADE GEOLÓGICA & $\begin{array}{l}\text { FORMAÇÃO } \\
\text { PRINCIPAL }\end{array}$ & ÁREA (ha) & $\begin{array}{l}\text { \% DA } \\
\text { ÁREA }\end{array}$ & $\begin{array}{l}\text { VULNERABILIDADE } \\
\text { (Crepani et al. 2001) }\end{array}$ \\
\hline 1 & Suíte Intrusiva Alto Candeias & Granitos & $22.544,65$ & $5,87 \%$ & 1,1 \\
\hline 2 & Suíte Intrusiva Santo Antônio & Granitos & $53.873,46$ & $14,02 \%$ & 1,1 \\
\hline 3 & Suíte Intrusiva São Lourenço & Granitos & $13.666,21$ & $3,56 \%$ & 1,1 \\
\hline 4 & Suíte Intrusiva Teotônio & Granitos & 432,55 & $0,11 \%$ & 1,1 \\
\hline 5 & Complexo Jamari & Gnaisses & $221.077,62$ & $57,53 \%$ & 1,3 \\
\hline 6 & Formação Palmeiral & Arenitos Quartzosos & $34.054,54$ & $8,86 \%$ & 2,4 \\
\hline 7 & Aluviões Holocênicos & Aluviões & 732,1674 & $0,19 \%$ & 3,0 \\
\hline 8 & Cobertura Detrito Laterítica & $\begin{array}{l}\text { Depósitos Argilo- } \\
\text { Arenosos }\end{array}$ & $3.918,08$ & $1,02 \%$ & 3,0 \\
\hline 9 & Formação Jaci-Paraná & Areia & $33.988,44$ & $8,84 \%$ & 3,0 \\
\hline
\end{tabular}


De modo geral a vulnerabilidade sobre a variável geomorfologia foi baixa, isso levando em conta a baixa amplitude altimétrica, relevo pouco dissecado e menores declividades associado às planícies dos grandes rios identificados na área de estudo. Para Thompson e Fidalgo (2013), a declividade e o comprimento de rampa são variáveis importantes para estudos de vulnerabilidade dos solos. Por isso, os autores corroboram afirmando que a elaboração de mapas de declividade tem grande importância para estudos da vulnerabilidade das terras aos processos erosivos (THOMPSON e FIDALGO, 2013).

Assim, a maior parte da área tem características planas onde a declividade não passa de $2 \%$. Por consequência, a maior parte da área está sobre influência de geomorfologia moderadamente estável.

A análise sobre os solos levou em conta também a estrutura do solo, tipo e quantidade das argilas, permeabilidade e profundidade do solo e a presença de camadas impermeáveis. Assim, solos com maior teor de argilas recebem valores próximos a 1 , enquanto solos mais arenosos recebem valores próximos a 3. Contudo, para Gomes (2000, p. 103) "a principal característica considerada para a análise dos solos é o seu grau de maturidade do solo, ou seja, o quão antigo é o solo, pois, quanto mais maduro, maior a profundidade e menor é a perda de solo". Para Santana et al. (2007) a suscetibilidade a erosão também se revela a capacidade de resistir ao desprendimento e transporte pela chuva e enxurrada.

Para a área de estudo foram identificadas sete classes de solos (Figura 3) sendo elas (1) Latossolo Amarelo, (2) Latossolo Vermelho-Amarelo, (3) Argissolo VermelhoAmarelo, (4) Cambissolo Háplico, (5) Plintossolo Argilúvico, (6) Neossolo Litólico e (7) Neossolo Flúvico.

De acordo com o Sistema Brasileiro de Classificação de Solos (EMBRAPA, 2006), os Latossolos de modo geral, são solos bastantes intemperizados, apresentando como principais minerais derivados da argila, caolinita, gipisita, minerais amorfos e sesquióxidos de ferro e alumínio. Esta classe é responsável pelo solo está presente em mais de $90 \%$ da área estudada, totalizando uma área de 349.186,71 ha. Por ser um solo antigo e profundo, recebe o valor de 1,0 na escala de vulnerabilidade natural a perda de solos de Crepani et al. (2001), sendo classificado como estável.

Por outro lado, no "grupo" dos solos considerados mais vulneráveis estão presentes as classes Plintossolo e Neossolo, recebendo ambos o valor de 3,0 na escala de vulnerabilidade natural a perda de solos de Crepani et al. (2001). Adamy (2005) cita que, de forma geral, os Neossolos são solos minerais, podem se desenvolver arenoquartzosos, rasos e pouco desenvolvidos, contém percentagem de argila menor que $15 \%$. Em geral ocorrem em áreas de relevo plano a suave ondulado e de fertilidade natural muito baixa. São solos com grande susceptibilidade a erosão. Os Neossolos podem ser encontrados em uma pequena faixa ao centro da área de estudo e é responsável por $2,55 \%$ da área total. 


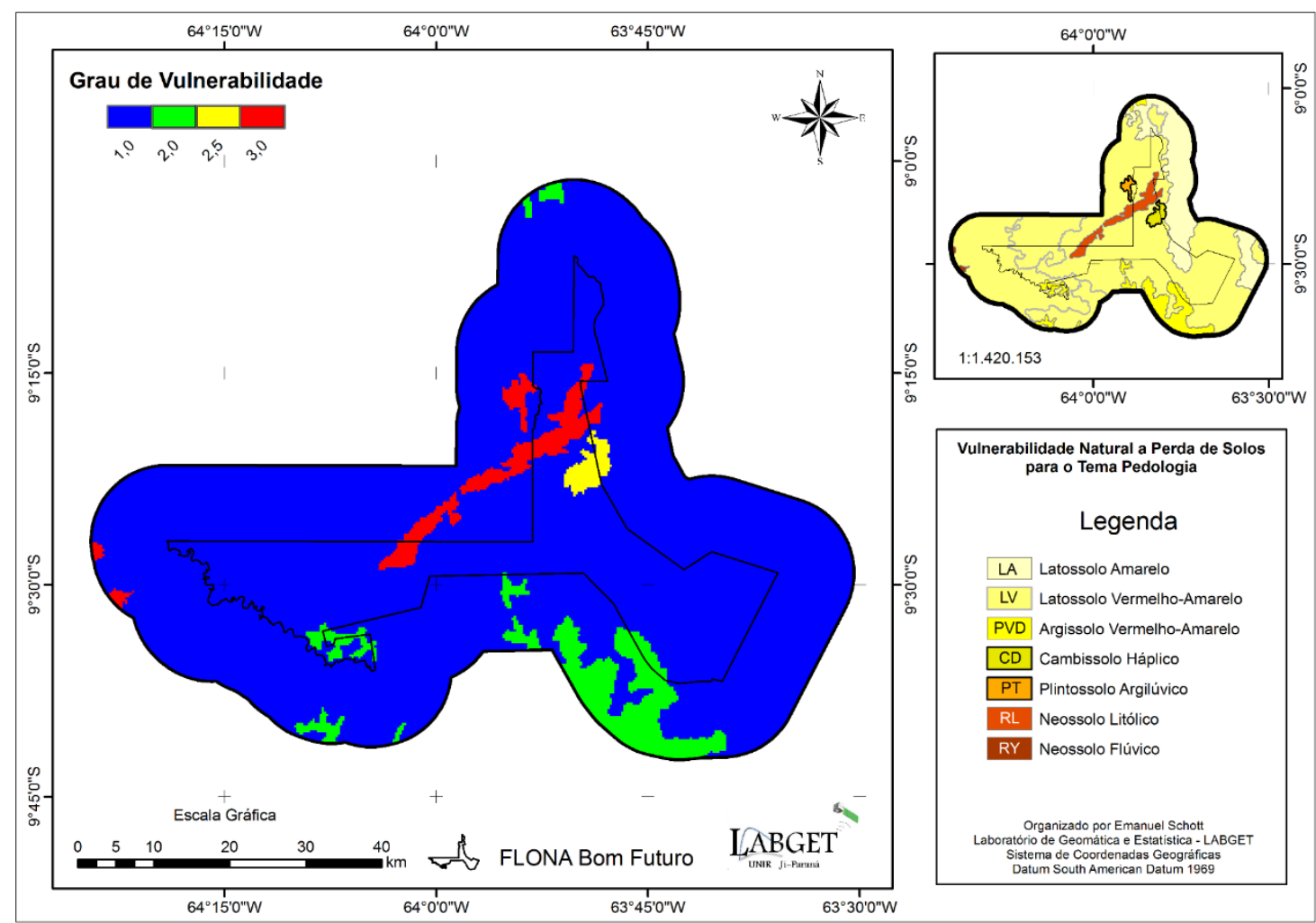

Figura 3. Vulnerabilidade a perda de solo para a variável de análise dos solos.

Adamy (2005) afirma que os Plintossolos são solos medianamente desenvolvidos, pouco profundos, mal ou imperfeitamente drenados, tendo como característica fundamental um horizonte plíntico, definido pela presença de plintita em quantidade igual ou superior a 15\% e espessura mínima de $15 \mathrm{~cm}$. Apenas 1.489,46 ha são compostos por esta classe, correspondendo a 0,26\% de toda a área de estudo.

O clima apresenta grande generalização na escala utilizada, por isso a variação foi insignificante, predominando o valor 1,7 de vulnerabilidade. Apesar disso, sabe-se que a intensidade das chuvas, principal variável do clima utilizada, pouco varia na área de estudo, que pode ser considerada pequena. De modo geral, os principais tipos de erosão hídrica são a laminar e por sulcos. O primeiro tipo consiste na remoção das camadas superficiais do solo, gerando impacto das gotas, já na erosão por sulcos, o escoamento superficial concentra-se em pequenas linhas de água que vão se alargando progressivamente (CASTILHO e FILHO, 2001).

É importante ressaltar que apesar do grande índice pluviométrico, a região amazônica possui o período chuvoso mais alongado, o que faz com que a intensidade pluviométrica em $\mathrm{mm} / \mathrm{mês}$ seja menor em relação a outras regiões e, consequentemente, o peso definido na escala de vulnerabilidade natural a perda de solos é menor. Como exemplo, pode ser citado o trabalho de Gomes (2000) realizado na região do semiárido, onde foram encontrados valores de precipitação de até um quarto do apresentado para a região da FLONA Bom Futuro, porém, com o período 
VULNERABILIDADE NATURAL À PERDA DE SOLOS NA FLONA BOM FUTURO E SEU ENTORNO PRÓXIMO/ESTADO DE RONDÔNIA

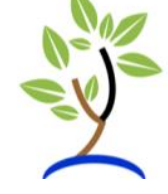

chuvoso menor. Isto fez com que os valores de vulnerabilidade natural a perda de solos se apresentem próximos a 3,0 para aquela região, caracterizados como vulneráveis.

Na variável de uso e cobertura dos solos dá-se destaque para a vegetação, pois a mesma cumpre um importante papel na proteção do solo contra a força hídrica exercida pelas águas pluviais, servindo como uma "barreira" entre a água e o solo (CASTILHO e FILHO, 2001). Além disso, "as raízes propiciam uma maior sustentação mecânica do solo e as raízes mortas favorecem a existência de canais no solo (drenagem) onde a água pode penetrar, diminuindo a quantidade de água que escoa na superfície do solo (Portugal, 2000 apud CASTILHO e FILHO, 2001, p. 1). Inclusive, Sousa et al. (2016), revela que até mesmo o capim, que possui baixa densidade de biomassa, promove redução de perdas de solos, se comparado com o solo sem cobertura vegetal.

Assim, na área de estudo a vegetação nativa é quase totalmente preservada, principalmente na terra indígena Karitiana, onde a vegetação nativa da zona de amortecimento da FLONA se encontra totalmente inalterada, enquanto que na RESEX Jaci-Paraná, encontram-se antropizadas, totalizando $6.447,33$ há. A maior parte dessas áreas é composta por Vegetação Secundária (4.068,26 ha), seguida de Pastagem (2.379,06 ha). Estas informações estão dispostas na Tabela 4.

Tabela 4 - Classes de uso na Zona de Amortecimento da FLONA Bom Futuro em intersecção com a RESEX Jaci-Paraná.

\begin{tabular}{llcc}
\hline$\#$ & CLASSE & ÁREA (ha) & $\begin{array}{c}\text { \% DA AREA } \\
\text { TOTAL }\end{array}$ \\
\hline $\mathbf{1}$ & Nativa & $\mathbf{4 4 . 8 1 9 , 7 3}$ & $\mathbf{8 7 , 4 2 \%}$ \\
1.1 & Vegetação Nativa & $44.819,73$ & $87,42 \%$ \\
$\mathbf{2}$ & Antrópica & $\mathbf{6 . 4 4 7 , 3 3}$ & $\mathbf{1 2 , 5 8 \%}$ \\
2.1 & Vegetação Secundária & $4.068,27$ & $7,94 \%$ \\
2.2 & Pastagem & $2.379,06$ & $4,64 \%$ \\
\hline \multicolumn{2}{c}{ ÁREA TOTAL } & $\mathbf{5 1 . 2 6 7 , 0 6}$ & $\mathbf{1 0 0 , 0 0 \%}$ \\
\hline
\end{tabular}

A classe de cobertura Floresta Ombrófila Aberta é considerada como uma paisagem natural e segundo o IBGE (2012), a mesma é considerada por muitos anos como um tipo de transição entre a Floresta Amazônica e áreas extra-Amazônicas. Apresenta quatro faciações florísticas que alteram a fisionomia ecológica da Floresta Ombrófila Densa, imprimindo-Ihe espaços abertos, daí advindo o nome adotado (IBGE, 2012, p. 74). Por apresentar estas características, Crepani et. al (2001) define que o peso 1,2 é o adotado para este tipo vegetal, sendo considerado estável.

A região da zona de amortecimento com maior supressão da vegetação nativa se encontra na APA Rio Pardo. Como pode ser visto na Tabela 7, 47,90\% da área é composta por áreas antropizadas (Tabela 5). Vale ressaltar que este tipo de UC permite a ocupação humana e até mesmo a presença de núcleos urbanos em seus limites, isto explica a grande área ocupada. 
VULNERABILIDADE NATURAL À PERDA DE SOLOS NA FLONA BOM FUTURO E SEU ENTORNO PRÓXIMO/ESTADO DE RONDÔNIA

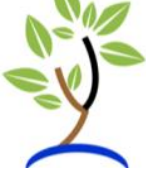

Tabela 5 - Classes de uso na área de entorno da FLONA Bom Futuro em intersecção com a APA Rio Pardo.

\begin{tabular}{rlcc}
\hline \# & CLASSE & ÁREA (ha) & $\begin{array}{c}\text { \% DA AREA } \\
\text { TOTAL }\end{array}$ \\
\hline $\mathbf{1}$ & Nativa & $\mathbf{2 8 . 7 0 7 , 8 4}$ & $\mathbf{5 2 , 1 0 \%}$ \\
1.1 & Vegetação Nativa & $28.707,84$ & $52,10 \%$ \\
$\mathbf{2}$ & Antrópica & $\mathbf{2 6 . 3 9 6 , 9 1}$ & $\mathbf{4 7 , 9 0 \%}$ \\
2.1 & Vegetação Secundária & $4.503,06$ & $8,17 \%$ \\
2.2 & Pastagem & $21.893,85$ & $39,73 \%$ \\
\hline \multicolumn{2}{c}{ ÁREA TOTAL } & $\mathbf{5 5 1 , 0 3}$ & $\mathbf{1 0 0 , 0 0 \%}$ \\
\hline
\end{tabular}

Nas regiões onde não estão presentes outras unidades de conservação, a supressão da vegetação nativa chega próximo aos $30 \%$, sendo que a maior área é composta por Pastagem, totalizando uma área de $31.778,20$ ha (22,50 \%) (Tabela 6).

Tabela 6 - Classes de uso na área de entorno sem a presença de outras UC.

\begin{tabular}{rlcc}
\hline$\#$ & CLASSE & ÁREA (ha) & $\begin{array}{c}\text { \% DA AREA } \\
\text { TOTAL }\end{array}$ \\
\hline $\mathbf{1}$ & Nativa & $\mathbf{9 9 . 0 5 9 , 7 6}$ & $\mathbf{7 0 , 1 3 \%}$ \\
1.1 & Vegetação Nativa & $99.059,76$ & $\mathbf{7 0 , 1 3 \%}$ \\
$\mathbf{2}$ & Antrópica & $\mathbf{4 2 . 1 9 4 , 9 9}$ & $\mathbf{2 9 , 8 7 \%}$ \\
2.1 & Vegetação Secundária & $10.293,49$ & $7,29 \%$ \\
2.2 & Pastagem & $31.778,20$ & $22,50 \%$ \\
2.3 & Queimada & 123,30 & $0,09 \%$ \\
\hline \multicolumn{2}{c}{ ÁREA TOTAL } & $\mathbf{1 4 1 . 2 5 4 , 7 5}$ & $\mathbf{1 0 0 , 0 0 \%}$ \\
\hline
\end{tabular}

No interior da FLONA Bom Futuro, a retirada da vegetação nativa chega a $12,41 \%$ (Tabela 7), um valor elevado considerando que nas FLONAS, somente é permitido a exploração mediante projeto de manejo.

Tabela 7 - Classes de uso no interior da FLONA Bom Futuro.

\begin{tabular}{rlcc}
\hline \# & CLASSE & ÁREA (ha) & $\begin{array}{c}\text { \% DA AREA } \\
\text { TOTAL }\end{array}$ \\
\hline $\mathbf{1}$ & Nativa & $\mathbf{8 2 . 7 8 7 , 9 6}$ & $\mathbf{8 7 , 5 9 \%}$ \\
1.1 & Vegetação Nativa & $82.787,96$ & $\mathbf{8 7 , 5 9 \%}$ \\
$\mathbf{2}$ & Antrópica & $\mathbf{1 1 . 7 3 3 , 5 2}$ & $\mathbf{1 2 , 4 1 \%}$ \\
2.1 & Vegetação Secundária & $6.766,73$ & $\mathbf{7 , 1 6 \%}$ \\
2.2 & Pastagem & $4.165,69$ & $4,41 \%$ \\
2.3 & Queimada & 801,10 & $0,85 \%$ \\
\hline \multicolumn{2}{c}{ ÁREA TOTAL } & $\mathbf{9 4 . 5 2 1 , 4 8}$ & $\mathbf{1 0 0 , 0 0 \%}$ \\
\hline
\end{tabular}


A espacialização do uso e cobertura do solo está contida na Figura 4, em que se observou áreas de desmatamento na porção norte e sul, onde ocorreu então a suscetibilidade a erosão. Segundo o IBGE (2012), regiões onde houveram intervenções humanas para o uso da terra, seja mineração, agricultura ou pecuária e foram abandonadas estão sujeitas a regeneração natural, caracterizando uma área de Vegetação Secundária.

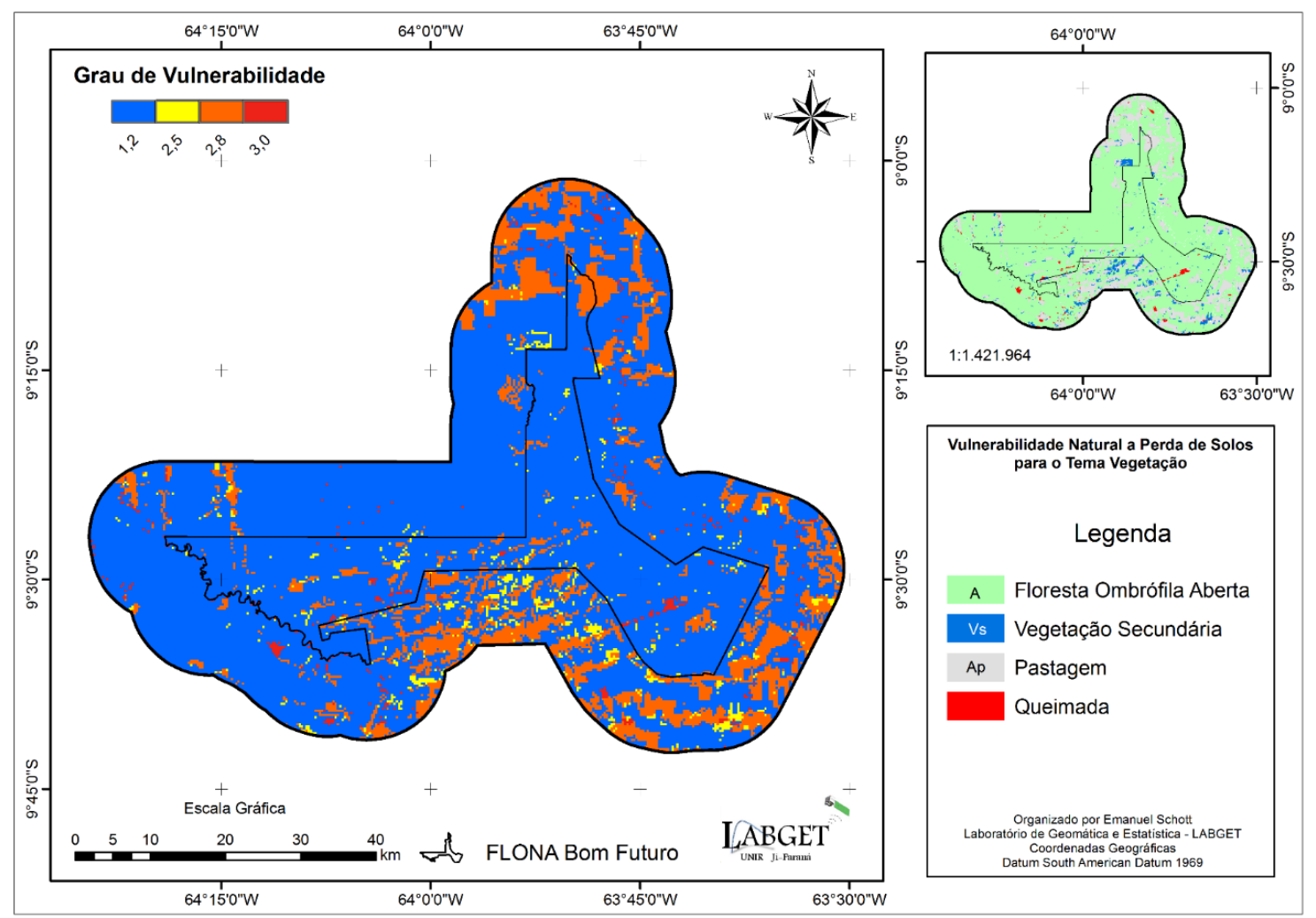

Figura 4 - Vulnerabilidade a perda de solo para a variável uso e cobertura do solo.

Esta vegetação que surge, tende a obedecer aos parâmetros ecológicos do ambiente, porém, a regeneração segue o ritmo de recuperação do solo degradado. Sendo assim, até que haja a regeneração completa, a vegetação pode não ter as mesmas características naturais presentes na região. Para estas UTB foi adotado o peso de 2,5 na Escala de Vulnerabilidade Natural a Perda de Solos, sendo caracterizado como uma área moderadamente vulnerável.

A Pastagem é composta por gramíneas, e de acordo com Crepani et al. (2001), recebe peso de 2,8 para esta vegetação, sendo considerada uma UTB vulnerável. Segundo Castilho e Filho (2001), áreas de pastagens oferecem grandes riscos de desprendimento dos solos devido à exposição.

Por fim, as Queimadas são áreas onde a vegetação primária foi retirada e a limpeza foi feita através de fogo, deixando o solo completamente exposto a força das águas pluviais. Isto faz com que o solo fique altamente vulnerável, por isto, o valor máximo $(3,0)$ é adotado na Escala de Vulnerabilidade Natural a Perda de Solos. 
VULNERABILIDADE NATURAL À PERDA DE SOLOS NA FLONA BOM FUTURO E SEU ENTORNO PRÓXIMO/ESTADO DE RONDÔNIA

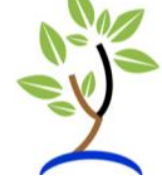

Após realizadas análises individuais, ou seja, por temas, nesta sessão são apresentados os resultados finais do trabalho, onde as informações referentes a cada tema são reunidas em um único mapa (FIGURA 6). A síntese dos resultados está apresentada na Tabela 8.

Quanto ao grau de estabilidade/vulnerabilidade, foi constatado que 187.110,38 ha, ou $48,87 \%$ da área estão sobre regime estável. A grande participação de Latossolos e de rochas graníticas é a responsável por esta característica. Essas formações têm características de difícil intemperismo, o que diminui o risco de erosão.

Tabela 8 - Grau de Vulnerabilidade/Estabilidade para a FLONA Bom Futuro e seu entorno.

\begin{tabular}{lcc}
\hline GRAU DE VULNERABILIDADE & AREA (ha) & \% DA ÁREA TOTAL \\
\hline Estável & $187.110,38$ & $48,87 \%$ \\
Moderadamente Estável & $166.875,88$ & $43,59 \%$ \\
Mediamente Estável/Vulnerável & $28.019,12$ & $7,32 \%$ \\
Moderadamente Vulnerável & 851,12 & $0,22 \%$ \\
Vulnerável & 0,00 & $0,00 \%$ \\
\hline
\end{tabular}

As áreas moderadamente estáveis estão presentes em 43,59\% da área total (166.875,88 ha), sendo as áreas antropizadas e com presença de geologias arenosas as principais com essas características. $28.019,12$ ha $(7,32 \%)$ estão com regime Mediamente Estável/Vulnerável.

As regiões correspondentes a áreas mediamente estáveis/vulneráveis são aquelas onde se encontram solos arenosos, como o Neossolo e o Plintossolo e, onde se encontram declividades maiores de $20 \%$, correspondendo uma área de 851,12 ha, ou menos de $1 \%$ de toda a área de estudo.

Regiões vulneráveis não foram identificadas, isso se deu principalmente pela presença de uma grande área coberta por Latossolos e rochas graníticas, além disso, a variável clima pouco interferiu neste quesito devido à baixa intensidade pluviométrica da Amazônica. Porém, num cenário hipotético onde toda a vegetação fosse retirada, o grau de vulnerabilidade dos solos aumentaria. Como pode ser visto na Tabela 9, não haveriam áreas estáveis, sendo que as áreas moderadamente estáveis receberiam um aumento de 105.713,22 ha.

Tabela 8 - Grau de Vulnerabilidade/Estabilidade para um cenário hipotético onde toda a vegetação fosse retirada.

\begin{tabular}{lcc}
\hline GRAU DE VULNERABILIDADE & AREA (ha) & \% DA ÁREA TOTAL \\
\hline Estável & 0,00 & $0 \%$ \\
Moderadamente Estável & $272.589,10$ & $71,04 \%$ \\
Mediamente Estável/Vulnerável & $98.929,49$ & $25,78 \%$ \\
Moderadamente Vulnerável & $12.168,23$ & $3,17 \%$ \\
Vulnerável & 0,00 & $0 \%$ \\
\hline
\end{tabular}


Ainda neste cenário, áreas moderadamente vulneráveis teriam um aumento de aproximadamente $1.500 \%$. Estas análises comprovam que, apesar da grande retirada da vegetação nativa presente na FLONA Bom Futuro e seu entorno, a vegetação restante cumpre um importante papel na conservação do solo, sendo de fundamental importância a sua conservação (Figura 5).

Nesse cenário da síntese dos resultados reforça-se o papel da terra indígena na conservação da paisagem e que apesar das alterações observadas a área os recursos mapeados cumprem o papel de proteção dos solos. Este resultado é corroborado pelos trabalhos de Guidelli (2013) e Linhares (2013), que observaram a importância das terras indígenas Kwazá do Rio São Pedro e Mequéns, respectivamente para a conservação da vegetação em áreas inundáveis e dos Neossolos na região mais a sul de Rondônia. Na intersecção entre a zona de amortecimento da FLONA Bom Futuro e a TI, a floresta se encontra preservada, contrapondo a outras áreas na região de estudo.

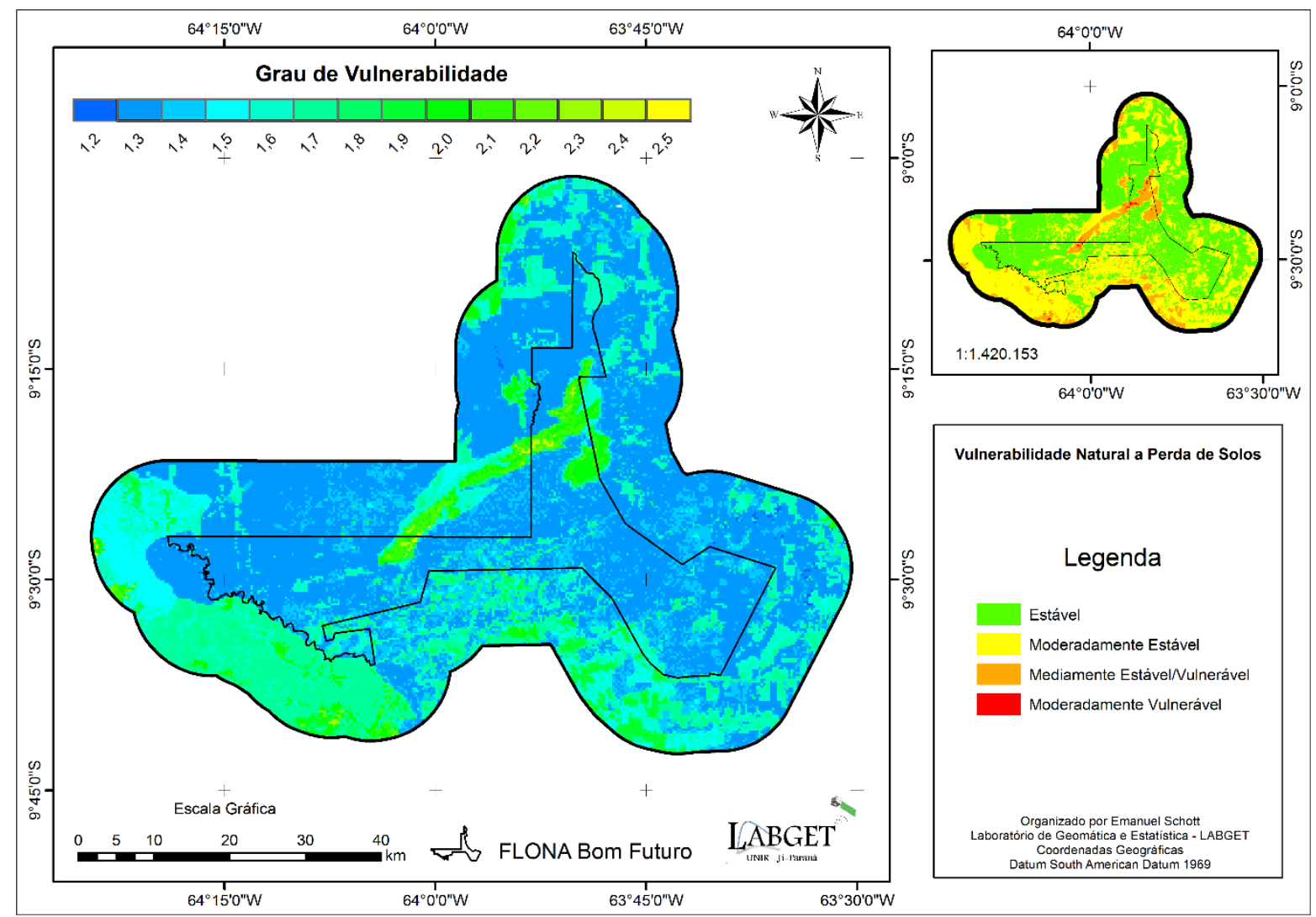

Figura 6. Vulnerabilidade Natural a Perda de Solos para a FLONA Bom Futuro e seu entorno. 
VULNERABILIDADE NATURAL À PERDA DE SOLOS NA FLONA BOM FUTURO E SEU ENTORNO PRÓXIMO/ESTADO DE RONDÔNIA

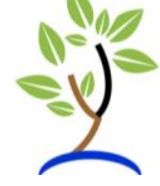

\section{CONCLUSÕES}

Os resultados permitiram as seguintes conclusões:

- 57,53 \% da área em estudo encontra-se sobre ambiente geológico estável, predominam gnaisses, de vulnerabilidade natural à perda de solo considerada baixa na escala de Crepani et al. (2001);

- A declividade não ultrapassa $2 \%$ e observou baixa amplitude altimétrica;

- Predominaram solos profundos e bem drenados que foram atribuídos peso 1,0 na escala de vulnerabilidade natural a perda de solos. Apenas disso, uma pequena área foi caracterizada como Neossolo (2,55\% da área total); contudo, nessas áreas os solos desse tipo foram determinantes para a caracterização das áreas classificadas como moderadamente vulnerável;

- A Zona de Amortecimento da FLONA Bom Futuro em intersecção com a RESEX Jaci-Paraná apresentou $87,42 \%$ de sua área recoberta por florestas; em intersecção com a APA Rio Pardo a área recoberta com vegetação diminuiu para $52,10 \%$ e com a terra indígena a vegetação está conservada; ou seja, a APA Rio Pardo foi, dentre as áreas especiais de entorno, a que menos contribui para a estabilidade do meio físico no entorno da FLONA do Bom Futuro;

- No interior da FLONA do Bom Futuro 87,59\% de florestas estão conservadas, apesar da identificação de focos de áreas queimadas e pastagens;

- Por fim, o cenário favorável de conservação das florestas aliados às características edafoclimáticas da área em estudo permitiu concluir, a partir da metodologia adota, que não há, para o período recente, áreas consideradas vulneráveis à perda de solos no interior e no entorno da FLONA do Bom Futuro.

\section{REFERÊNCIAS}

ABDON, M. M. Os impactos ambientais no meio físico - erosão e assoreamento na bacia hidrográfica do Rio Taquari, MS, em decorrência da pecuária. 2004. 322f. Tese (Doutorado em Ciências da Engenharia Ambiental) - Escola de Engenharia de São Carlos, Universidade de São Paulo, 2004.

ADAMY, A. Zoneamento geoambiental de Pimenta Bueno. 2005. $161 \mathrm{f}$. Dissertação (Mestrado em Desenvolvimento Regional e Meio Ambiente) - Núcleo de Ciências e Tecnologia, Fundação Universidade Federal de Rondônia, 2005.

ASNER, G.P.; LOARIE, S.R.; HEYDER, U. Combined effects of climate and land-use change on the future of humid tropical forests. Conservation Letters, v. 3, №. 6 , p. 395-403, 2010. Disponível em: http://onlinelibrary.wiley.com/doi/10.1111/j.1755263X.2010.00133.x/epdf. Acesso em: 11/02/2017. 
VULNERABILIDADE NATURAL À PERDA DE SOLOS NA FLONA BOM FUTURO E SEU ENTORNO PRÓXIMO/ESTADO DE RONDÔNIA

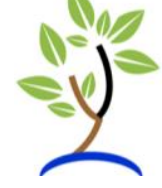

CÂMARA, G.; SOUZA, R. C. M.; FREITAS, U. M.; GARRIDO, Juan. SPRING: Integrating remote sensing and GIS by object-oriented data modelling. Computers \& Graphics, v. 20, n. 3, p. 395-403, 1996. Versão 5.1.1. Disponível em: http://www.dpi.inpe.br/cursos/ser303/spring_paper.pdf. Acesso em: 05 maio de 2016.

CARVALHO, J. C.; SALES, M. M.; SOUZA, N. M.; MELO, M. T. S.; Processos erosivos no Centro-Oeste brasileiro. Brasília: FINATEC, 2006, 245p.

CASTELLO, L; MCGRATH, D.G.; HESS, L.L.; COE, M.T.; LEFEBVRE, P.A.; PETRY, P.; MACEDO, M.N.; RENÓ, V.; ARANTES, C.C. The vulnerability of Amazon freshwater ecosystems. Conservation Letter, v. 6, №. 4, p. 217-229, 2013. Disponível em: http://onlinelibrary.wiley.com/doi/10.1111/conl.12008/full. Acesso em: 08/08/2017.

CASTILHO, C.P.G.; FILHO, J.T. A importância da cobertura vegetal na atenuação da precipitação que atinge o solo - estudo de caso: cultura de cana- de-açúcar. In: SIMPÓSIO NACIONAL DE CONTROLE DE EROSÃO, 7., Goiânia, 2001. XII Simpósio Nacional de Controle de Erosão, Proceedings, ... Goiânia, 03 a 06 de maio de 2001. Disponível

em: http://www.labogef.iesa.ufg.br/links/simposio_erosao/articles/T011.pdf. Acesso em: 13 de maio de 2017.

CAVALCANTE, D. G.; PINHEIRO, E. S.; MACEDO, M. A.; MARTINOT, J. F.; NASCIMENTO, A. Z. A.; MARQUES, J. P. C. Análise da Vulnerabilidade Ambiental de um Fragmento Florestal Urbano na Amazônia: Parque Estadual Sumaúma.

Sociedade \& Natureza, v. 22, №. 2, p. 391-403, ago. 2010. Disponível em: http://www.seer.ufu.br/index.php/sociedadenatureza/article/view/10020. Acesso em: 12/02/2017.

CORDEIRO, J.P.; BARBOSA, C.C.F. CÂMARA, G. Álgebra de Campos e objetos. In: CÂMARA, G.; MONTEIRO, A.M.; DAVIS, C. (Orgs.). Geoprocessamento: Teoria e Aplicações. São Paulo: INPE, 2007. 8, 1-26. Disponível em: $<$ http://www.dpi.inpe.br/gilberto/livro/>.

Acesso em: 13 ago. 2011.

CREPANI, E.; MEDEIROS, J.S.; AZEVEDO, L.G.; DUARTE, V.; HERNANDEZ, P.; FLORENZANO, T; BARBOSA, C.. Sensoriamento Remoto e Geoprocessamento Aplicados ao Zoneamento Ecológico-Econômico e ao Ordenamento Territorial. São José dos Campos: INPE, 2001, 103p.

EMPRESA BRASILEIRA DE PESQUISAS AGROPECUÁRIAS. Sistema brasileiro de classificação de solos. Rio de Janeiro, RJ: EMBRAPA SOLOS, 2006. ISBN: 8585864-19-2.

FARIA, A.L.L.; SILVA, J.X.; GÓES, M.H.B.. Análise ambiental por geoprocessamento em áreas com susceptibilidade a erosão do solo na Bacia Hidrográfica do Ribeirão do 
VULNERABILIDADE NATURAL À PERDA DE SOLOS NA FLONA BOM FUTURO E SEU ENTORNO PRÓXIMO/ESTADO DE RONDÔNIA

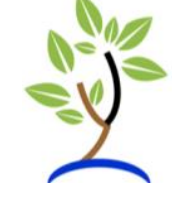

Espirito Santo, Juiz de Fora, MG. Caminhos de Geografia, v. 4, №. 9, p. 50-65, jun/ 2003.

Disponível

em:

http://www.seer.ufu.br/index.php/caminhosdegeografia/article/viewFile/15308/8607.

Acesso em: 13/08/2017.

FERREIRA, L.V.; VENTICINQUE, E.; ALMEIDA, S. O desmatamento na Amazônia e a importância das áreas protegidas. Estudos Avançados, v. 19, №.53, p.1-10, 2005. Disponível em: http://www.scielo.br/scielo.php?script=sci_arttext\&pid=S010340142005000100010 Acesso em: 24/03/2017.

FERREIRA, LV.; PEREIRA, J.LG. CUNHA, D.A.; MATOS, D.C.L.; JUAN, P.M.S. The Amazon is suitable for forestry, and the creation of new States can lead to increased deforestation in the Brazilian Amazon. Estudos Avançados, v. 26, №. 74, p. 187-200, 2012. Disponível em: http://www.scielo.br/pdf/ea/v26n74/en a13v26n74.pdf . Acesso em: 08/04/2017.

FONSECA, A., SALOMÃO, R., Ribeiro, J.; SOUZA JUNIOR, C. 2017. Ameaça e pressão de desmatamento em Áreas Protegidas: SAD de agosto a novembro de 2016 (p. 1). Belém: Instituto do Homem e do Meio Ambiente da Amazônia (IMAZON).

GOMES, A.R. Avaliação da vulnerabilidade à perda de solo em região semi-árida utilizando sensoriamento remoto e geoprocessamento - área piloto de Parnamirim (PE). 165 f. Dissertação (Mestrado do Curso de Pós-Graduação em Sensoriamento Remoto) - Instituto Nacional de Pesquisas Espaciais, 2000. Disponível em: http://www.obt.inpe.br/pgsere/Gomes-A-R-2000/publicacao.pdf $\quad$ Acesso em: 26/05/2017.

GOMES, F.B.; BASTOS, A.S.; VARGAS, B.; CASTRO, M.M. Estudo da vulnerabilidade natural à erosão como subsídio para recuperação de áreas degradadas no entorno da floresta nacional do Jamari/RO. In: Congresso Brasileiro de Cartografia, 25., Curitiba, 21 a 24 de agosto de 2011. Anais... do XXV Congresso Brasileiro de Cartografia, Proceedings...Curitiba: INPE, 2011. p. 747-754. Disponível em: http://www.semeandosustentabilidade.org/publicacoes/47 ct07 vf.pdf Acesso em: $13 / 06 / 2017$.

GUTH, P. L. Perdas de solo e água por erosão hídrica em sistemas de culturas oleaginosas. Santa Maria, RS: UFSM, 2010. 85f. Dissertação (Mestrado em Ciência do Solo). Centro de Ciências Rurais, Universidade Federal de Santa Maria, 30 de março de 2010. Disponível em: http://w3.ufsm.br/ppgcs/images/Dissertacoes/PAULOLUIS-GUTH.pdf Acesso em: 25/05/2017.

GUIDELLI, A. C. Vulnerabilidade à erosão dos solos e seus reflexos para a Terra Indígena Kwaza e seu entorno, Parecis/Rondônia. 74 f. 2013. Monografia (Graduação em Engenharia Ambiental) - Departamento de Engenharia Ambiental, Fundação Universidade Federal de Rondônia, 2013. 
VULNERABILIDADE NATURAL À PERDA DE SOLOS NA FLONA BOM FUTURO E SEU ENTORNO PRÓXIMO/ESTADO DE RONDÔNIA

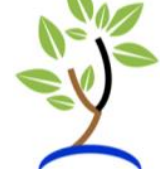

INSTITUTO BRASILEIRO DE GEOGRAFIA E ESTATISTICA. Manuais Técnicos em Geociências: Manual Técnico da Vegetação Brasileira. $2^{a}$ edição. Rio de Janeiro, RJ: IBGE, 2012.

INSTITUTO NACIONAL DE PESQUISAS ESPACIAIS. Sistema de ajuda online do Spring. $\quad 2012 . \quad$ Disponível em: http://www.dpi.inpe.br/spring/portugues/manuais.html Acesso em: 01 dez. 2013.

LAURANCE, W.F. When bigger is better: the need for Amazonian mega-reserves. TRENDS in Ecology and Evolution, v. 20 №. 20, p. 645-648, 2005. Disponível em: http://faculty.washington.edu/timbillo/Readings\%20and\%20documents/ABRIDGED\% 20READINGS\%20for\%20PERU/Laurance\%200ct\%2031\%5B1\%5D.\%202005.pdf Acesso em: 24/04/2017.

LINHARES, J. S. Geotecnologias aplicadas a análise da dinâmica de ocupação e da vulnerabilidade natural a perda de solos no município de Alto Alegre dos Parecis - Rondônia. 68 f. Monografia (Graduação em Engenharia Ambiental) Departamento de Engenharia Ambiental, Fundação Universidade Federal de Rondônia, 2013.

MENDES, A. M. Vulnerabilidade à perda de solo nos sistemas silvipastoris implantados em unidades de produção familiar no estado de Rondônia. In: Encontro de Produtos Agroecológicos de Mato Grosso do Sul, 3., Glória de Dourados, 16 a 18 de outubro de 2012. 3‥ Encontro de Produtos Agroecológicos de Mato Grosso do Sul, Proceedings...Glória de Dourados: CNPTIA, 16a 18 de outubro de 2012, 1-4. Disponível em: https://ainfo.cnptia.embrapa.br/digital/bitstream/item/72179/1/101 Vulnerabilidade-a-perda-de-solo-nos-sistemas-silvipastoris.pdf . 16 a 18 de out. 2012.

MINISTÉRIO DO MEIO AMBIENTE. 2009. Desocupação da FLONA Bom Futuro será negociada com moradores. Assessoria de Comunicação do Ministério do Meio Ambiente. Disponível em: http://www.ibama.gov.br/noticias-2009/desocupacao-daflona-bom-futuro-sera-negociada-com-moradores/ Acesso em: 25 abr. 2013.

MINISTÉRIO DO MEIO AMBIENTE (MMA). 2002. Mapas de cobertura vegetal dos biomas brasileiros. Disponível em: < http://mapas.mma.gov.br/mapas/aplic/probio/datadownload.htm>. Acesso em 21 dez. 2013.

NEPSTAD. P.; SCHWARTZMAN. S.; BAMBERGER. B.; SANTILLI, B.; RAY, D.; SCHLESINGER, P.; LEFEBVRE, P.; ALENCAR, A.; FRINZ, E. FISKE, G.; ROLLA, A. Inhibition of Amazon Deforestation and Fire by Parks and Indigenous Lands. Conservation Biology, v. 20, №. 1, p. 65-73, 2005.

REZENDE, M.G.G.; CANALEZ, G.G.; FRAXE, T.J.P. Protected Areas in the Amazon: forest management, conflict and social participation. Acta Scientiarum. Humam and Social Sciences, v. 39, №. 1, p. 63-70, Jan.-Apr., 2017. Disponível em: 
VULNERABILIDADE NATURAL À PERDA DE SOLOS NA FLONA BOM FUTURO E SEU ENTORNO PRÓXIMO/ESTADO DE RONDÔNIA

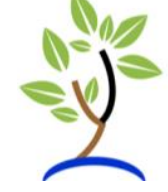

periodicos.uem.br/ojs/index.php/ActaSciHumanSocSci/article/download/33206/pdf.

Acesso em: 13/04/2017.

ROVANI, F.F. M. Zoneamento ecológico-econômico de Silveira Martins - RS. Boletim Goiano de Geografia, v. 37, №. 1, p. 140-157, jan./abr. 2017. Disponível em: https://revistas.ufg.br/bgg/article/download/46249/22772. Acesso em: 28/04/2017.

SANTANA, N. M.P.; CASTRO, S.S.; STONE, L.F.; SILVA, S.C. Chuvas, erosividade, erodibilidade, uso do solo e suas relações com focos erosivos lineares na alta bacia do Rio Araguaia. Sociedade \& Natureza, v. 19, № 2, p. 103-121, dez. 2007. Disponível

em:

http://www.labogef.iesa.ufg.br/labogef/arquivos/downloads/Neiva_Selma_Chuvas_Er osividade_2007_42821_43480.pdf. Acesso em: 23/05/2017.

SANTOS, A.M. Cartografia dos povos e das terras indígenas em Rondônia. 2014. 314 f. Tese (Doutorado em Geografia) - Programa de Pós-graduação em Geografia. Universidade Federal do Paraná, 15/11/2014.

SANTOS, A.M.; GOMIDE, M.L.C. A ocupação no entorno das terras indígenas em Rondônia, Brasil. Boletim Goiano de Geografia, v. 35, n. 3, p. 417-436, set./dez. 2015.

SANTOS, A.M.; MENDONÇA, A. G. Conflitos territoriais no Corredor Etnoambiental Tupi-Mondé - Rondônia-Mato Grosso. Terr@Plural, v. 10, n.2, p. 251-265, jul/dez. 2016.

SANTOS, A.M.; MOTA, V. C. Análise espacial dos usos e da cobertura da terra no pantanal dos rios Guaporé e Mamoré/Rondônia. Revista Brasileira de Geomática, v. 5 , n. 3, p. 433-452, jul/set. 2017

SOUSA, M.M.M.; PALÁCIO, J.C.; RIBEIRO FILHO, J.R.; ARAÚJO NETO, M..M.S.; MOURA. Influência da cobertura vegetal nas perdas de água e solo em parcelas de erosão no semiárido brasileiro. Revista Geonorte, Edição Especial 5, v.7, N.26, p.160-171, 2016. Disponível em: http://www.periodicos.ufam.edu.br/revistageonorte/article/view/2765. Acesso em: 13/12/2017.

SERVIÇO GEOLÓGICO DO BRASIL. 2006. Atlas pluviométrico do Brasil. Disponível em: http://www.cprm.gov.br/publique/cgi/cgilua.exe/sys/start.htm?infoid=1351\&sid=9 Acesso em: 20/12/2017.

THOMPSON, D.; FIDALGO, E. C.C. Vulnerabilidade dos Solos à Erosão: Estimativa da Perda de Solos na Bacia Hidrográfica do Rio Guapi-Macacu - RJ. Boletim de Pesquisa e Desenvolvimento, v. 237, p. 1-30, 2013. 
VERÍSSIMO, A.; ROLLA, A.; VEDOVETO, M.; FUTADA, S.M (Orgs.). Áreas protegidas na Amazônia brasileira: avanços e desafios. Belém: IMAZON; São Paulo: Instituto Socioambiental, 2011. Disponível em:

http://fas-amazonas.org/versao/2012/wordpress/wpcontent/uploads/2013/08/Areas Protegidas Amazonia.pdf Acesso em: 08/05/2017.

WINCANDER, R., MONROE, J. S. Essentials of geology. São Paulo: Cengage Learning, 2009. 329p. Traduzido por: CARNEIRO, M. A., 2009.

UNITED STATES GEOLOGICAL SURVEY. 2013. USGS Global Visualization Viewer. Disponível em http://glovis.usgs.gov . Acesso em 18 dez 2013.

Submetido em: 16/01/2018 Aceito para publicação em: 16/04/2018 